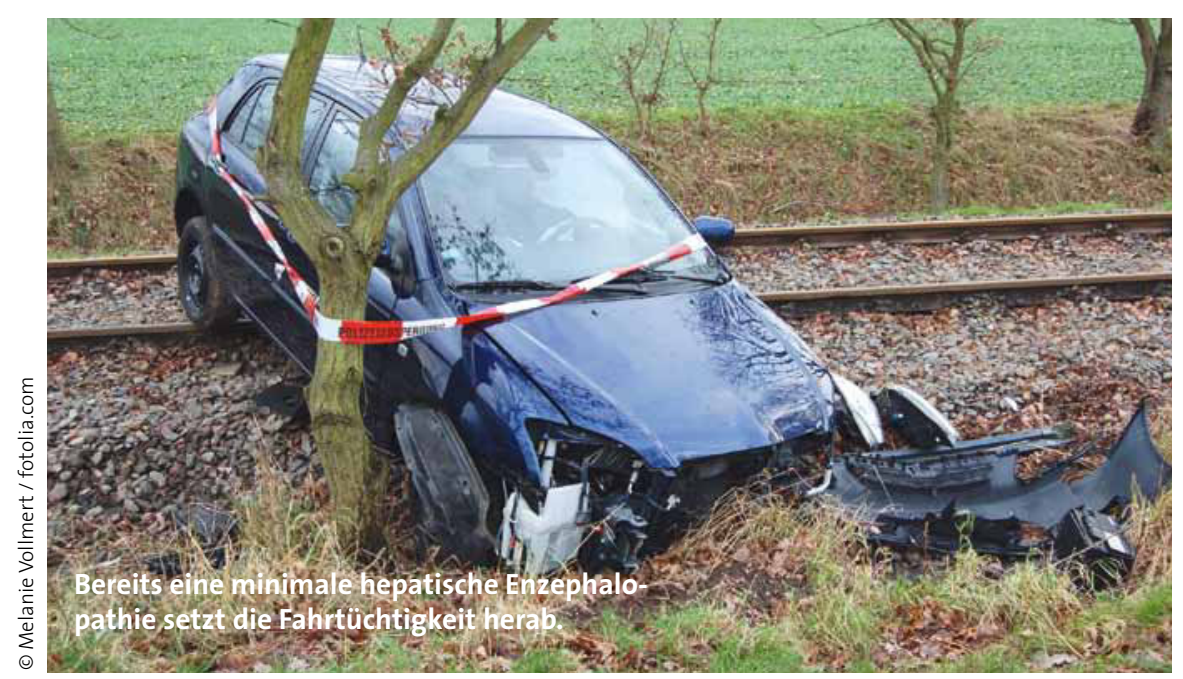

\title{
Hepatische Enzephalopathie erhöht Unfallgefahr
}

Die hepatische Enzephalopathie gehört zu den häufigsten Komplikationen einer Leberzirrhose. Jetzt konnte erstmals in einer Studie gezeigt werden, dass bereits eine minimale hepatische Enzephalopathie die Fahrtauglichkeit beeinträchtigt und somit das Unfallrisiko erhöht.

- Patienten mit bekannter Leberzirrhose wurden im Hinblick auf das Vorliegen einer minimalen hepatischen Enzephalopathie mittels psychometrischer Tests oder inhibitorischer Kontrolltests untersucht. Anschließend wurden die Patienten bezüglich Unfallereignisse bzw. Verkehrsdelikte über ein Jahr nachverfolgt.

Bei 167 Patienten mit Leberzirrhose fanden sich amtliche Eintragungen über Verkehrsdelikte, wobei Patienten mit minimaler hepatischer Enzephalopathie sehr viel häufiger betroffen waren als solche ohne diese Komplikation (17\% vs. $3 \%)$. Ähnlich waren die Ergebnisse im weiteren prospektiven Verlauf über ein Jahr ( $22 \%$ vs. $7 \%$ ).

\section{- J.S. Bajaj et al.}

Minimal hepatic encephalopathy is associated with motor vehicle crashes: The reality beyond the driving test. Hepatology 50 ; 1175-1183

\section{Kommentar}

Diese Ergebnisse zeigen eindrucksvoll, dass bereits eine minimale hepatische Enzephalopathie bei Patienten mit Leberzirrhose die Fahrtüchtigkeit deutlich beeinträchtigt und somit das Unfallrisiko erhöht. Doch welche Konsequenzen ergeben sich daraus? Zunächst einmal sollte bei jedem Patienten mit bekannter Leberzirrhose nach einer minimalen hepatischen Enzephalopathie gefahndet werden. Bei Nachweis einer solchen sollte der Patient ausdrücklich auf das erhöhte Unfallrisiko mit den sich eventuell daraus ergebenden haftungsrechtlichen Konsequenzen hingewiesen werden. Dies sollte auch schriftlich dokumentiert sein, damit der Patient im Falle eines Verkehrsunfalls nicht behaupten kann, man habe ihn auf dieses Risiko nicht hingewiesen, zumal betroffene $\mathrm{Pa}-$ tienten ihre Fahrtauglichkeit häufig überschätzen. Sollte der Patient sich darüber hinwegsetzen, muss im Einzelfall geprüft werden, ob eventuell auf behördlichem Wege über die Polizei ein Entzug der Fahrerlaubnis angestrebt werden sollte.

P. STIEFELhAGEN = 